\title{
The Hotspots and suggestions of MOOC research in China
}

\author{
Shenghu Tian ${ }^{1, \mathrm{a}}$,Jianfeng Yao ${ }^{1, \mathrm{~b}}{ }^{*}$, Fan $\mathrm{Yu}^{2, \mathrm{c}}$ and Tongyi Cui ${ }^{1, \mathrm{~d}}$ \\ ${ }^{1}$ Institute of Yunnan Business Research, Yunnan University of finance and economics, kunming 650221,China; \\ ${ }^{2}$ Experimental teaching management center,Yunnan University of finance and economics, kunming 650221,China;

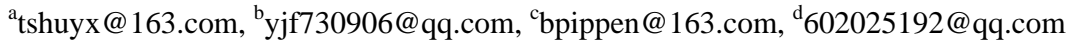 \\ *corresponding author
}

Abstract: The aim of this study is to examine research hotspots of MOOC in China.We conducted a keyword co-occurrence analysis of more than 6000 MOOC papers recorded in CNKI. The study reveals that there are five hotspots. In future, we should pay attention to the following aspects, including development strategy, propulsion mechanism,cooperation research and business-model innovation.

Keywords: MOOC, Knowledge map, Visualized analysis, Blended teaching.

\section{Introduction}

Massive Open Online Courses(MOOC) was praised as a "digital tsunami" in the history of education by John Hennessy, President of Stanford University. MOOC is regarded as a revolutionary teaching-model in China. MOOC began sweeping the globe in 2012, which has a great influence on all levels of education in different countries.Chinese scholars have conducted extensive exploration on MOOC. Some scholars try to find out the status of MOOC research in China and compare the research progress between domestic and foreign by visual analysis methods. For example,Wang Youmei professor et al. tried to sort out China's MOOC research routes, research hotspots and trends ${ }^{[1]}$.Dr. Chai Yanmei et al.tried to reveal the similarities and differences of relevant research between domestic and foreign ${ }^{[2]}$. Similar studies have made a preliminary interpretation and has certain guiding significance for MOOC practice. In particular, the visual research methods they use are worth learning. However, these studies can not accurately reflect the hotspots of MOOC research because of its smaller data capacity. With the maturity of MOOC research in China, more than 6000 papers have been recorded in CNKI. The scientific analysis of these papers can reflect more accurately the focus of MOOC research in China.That will be conducive to grasp the current situation of MOOC research in China,provide strong support for follow-up research,and promote international peers interaction.

\section{Research Methods}

Data acquisition:China National Knowledge Infrastructure(CNKI) is the most comprehensive and timely academic database in China. Most of the papers recorded in CNKI are evaluated by experts. In order to ensure the effectiveness, We used "MOOC","Massive Open Online Courses"as the keywords for retrieval in the title.6125 papers were retrieved. There were 6078 valid papers after removing the conference notices and other reports. Retrieve the date by May 7, 2017.

Research tools:In this paper, we used SATI3.2 and Netdraw for analysis tools. SATI3.2 is a special software for analysing bibliographic information,which can 
extract the specified field information, statistic entrie's frequency, and construct the co-occurrence matrix of knowledge units. Netdraw is also a special software for social network analysis, which is often used to draw knowledge maps cooperating with SATI3.2.The two softwares are widely used in library, information science, education, management and other fields, has been generally recognized by the academia.

Research process: The data handling process mainly includes the following steps. First, we saved the bibliographic information, and standardized keywords expression. Such as MOOC,MOOCs,Massive Open Online Courses are represented by MOOC. The University library and Public libraries are expressed in library, and so on. Second, We used SATI3.2 to extract keywords, conducted co-word analysis based on high frequency keywords,and obtained the high frequency keywords co-occurrence matrix. Third,We used Netdraw to draw high frequency keywords co-occurrence map(Fig.2). For this step, the matrix is processed with binaryzation,and set the threshold of the co-occurrence coefficient to 0.01 . It means that if the coefficient is greater than 0.01 , there is a close connection between keywords.If the coefficient is less than 0.01 , there is no connection. The specific data handling process is shown in fig.1.

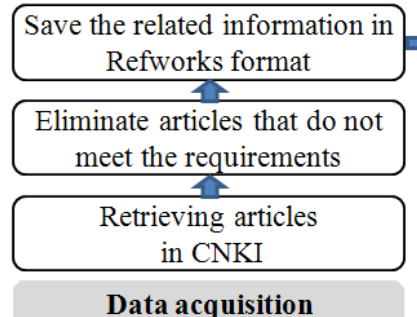

Data acquisition
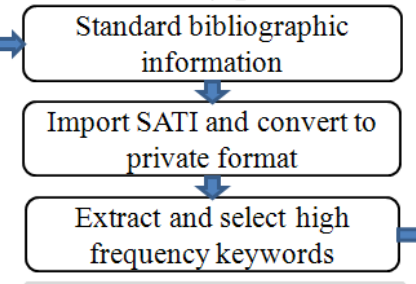

Statistical analysis

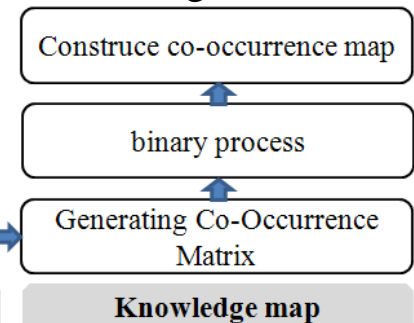

Knowledge map

Fig.1 Data handling process

In the study, 7088 keywords were extracted, the total frequency reached 23559. We chose keywords with frequency greater than 50 as high-frequency keywords (Table 1).There are 35 high frequency words, the total frequency is 9512, and the cumulative percentage is $40.38 \%$. Whitch reached the proportion requirements (27\%) for knowledge mapping analysis.

Table 1 The sorted list of high frequency keywords

\begin{tabular}{cccc}
\hline Numble & High frequency keywords & Frequency & Cumulative percentage \\
\hline 1 & MOOC & 4895 & $20.78 \%$ \\
2 & Educational reform & 468 & $22.76 \%$ \\
3 & Flipped Classroom & 461 & $24.72 \%$ \\
4 & Teaching model & 455 & $26.65 \%$ \\
5 & Library & 359 & $28.18 \%$ \\
6 & Higher Education & 212 & $29.08 \%$ \\
7 & College English & 193 & $29.90 \%$ \\
8 & Micro-lectures & 168 & $30.61 \%$ \\
9 & Online education & 160 & $31.29 \%$ \\
10 & Coping strategies & 158 & $31.83 \%$ \\
11 & Blended teaching & 156 & $32.49 \%$ \\
12 & Online courses & 137 & $33.07 \%$ \\
13 & Ideological and Political Theory Course & 136 & $33.65 \%$ \\
14 & Colleges and universities & 111 & $34.12 \%$ \\
15 & SPOC & 110 & $34.59 \%$ \\
16 & Reform & 100 & $35.01 \%$
\end{tabular}




$\begin{array}{lccc}17 & \text { Challenge } & 97 & 35.43 \% \\ 18 & \text { Teaching } & 87 & 35.80 \% \\ 19 & \text { Self-regulated learning } & 81 & 36.14 \% \\ 20 & \text { Influence } & 80 & 36.48 \% \\ 21 & \text { Learning process } & 76 & 36.80 \% \\ 22 & \text { Application } & 76 & 37.12 \% \\ 23 & \text { Curriculum construction } & 75 & 37.44 \% \\ 24 & \text { Classroom teaching } & 65 & 37.72 \% \\ 25 & \text { Instructional design } & 64 & 37.99 \% \\ 26 & \text { Higher Vocational Colleges } & 63 & 38.26 \% \\ 27 & \text { Online learning } & 63 & 38.52 \% \\ 28 & \text { Information technology } & 59 & 38.77 \% \\ 29 & \text { Teacher } & 56 & 39.01 \% \\ 30 & \text { Higher Vocational Education } & 55 & 39.25 \% \\ 31 & \text { Information literacy } & 55 & 39.48 \% \\ 32 & \text { Big data } & 54 & 39.71 \% \\ 33 & \text { Enlightenment } & 53 & 39.93 \% \\ 34 & \text { English teaching of vocational education } & 52 & 40.15 \% \\ 35 & \text { Information Literacy Education } & 52 & 40.38 \%\end{array}$

In order to find out the degree of association between the high-frequency keywords, and then discover the research hotspots of MOOC.We draw the high frequency keywords co-occurrence map, as shown in Fig.2. The node size shows the co-occurrence degree of the keywords. The more the keyword appears, the greater the node size. The lines indicate the closeness degree between the keywords. The thicker the line, the closer the connection. Nodes aggregated together show that the areas of knowledge represented by these keywords are more concerned, which are the hotspots of current research.

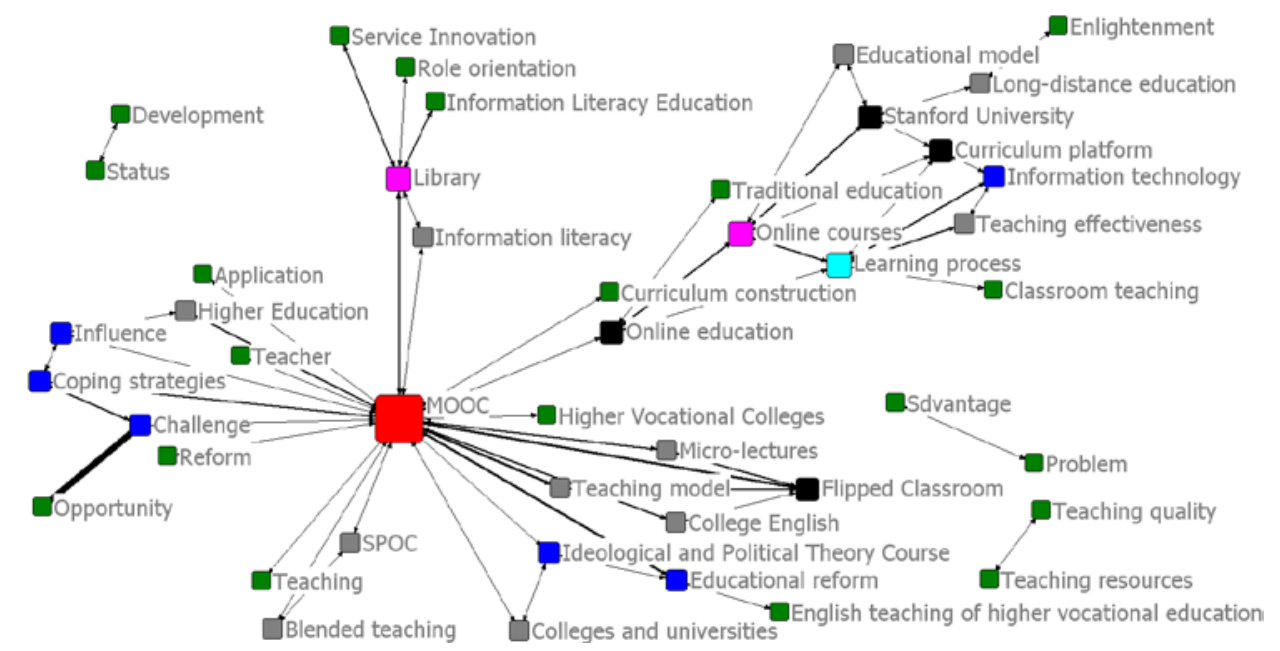

Fig.2 Co-occurrence map of high frequency keywords

\section{Results and Discussion}

\subsection{Research hotspots analysis(Fig.2)}

The impacts, challenges and countermeasures of MOOC on Higher Education. This hot topic is characterized by such keywords as "higher education, reform, influence, challenge, opportunity and coping strategy". MOOC not only challenges the traditional courses, but also has a significant impact on the teaching process, 
curriculum evaluation mechanism, teaching management model, faculty-student relationship. It even has a certain impact on the organizational function and faculty survival. This "MOOC storm" does have a powerful impact on China's colleges and universities $^{[3]}$. However, with the continuous emergence of high dropout rate and low pass rate, People begin to think calmly about the function value of MOOC for China's higher education. Generally speaking, MOOC contributes to the popularization, internationalization and democratization and helps to promote the quality of higher education. It may also use advanced information technology, such as big data analysis, to realize individualized teaching.But, People still worry that the spread of MOOC may bring "Matthew effect"-the stronger the stronger, the weaker the weaker-to higher education, and then change the pattern of higher education.

The key factors to improve the quality of MOOC and the enlightenments for traditional education and distance education. Keywords characterizing this hot topic include online education, online courses, learning process, course platform, Standford, information technology, teaching effectiveness, classroom teaching, traditional education, distance education and enlightenment. As a new type of educational model, MOOC has a strong tendency to enter into people's vision, which will inevitably challenge its validity. The key elements of concern include learning process, curriculum resources, curriculum platform, and teachers and students.But institutional design and government intervention to promote the growth of new things have not received much attention. Scholars believe that MOOC is the inevitable choice of merging distance education and traditional education ${ }^{[4]}$. They have been calling for changing the teaching model, exploring the reform of management system, changing the way of learning, improving the level of information-based teaching and the autonomous learning ability. The research of this subject category is the most abundant. On the one hand, it develops in a more intensive and meticulous way.On the other hand, it expands to the highly integrated road.

Research on flipped classroom and micro-lectures in College English and ideological and political theory course based on MOOC platform. This hot topic is mainly characterized by the keywords"College English, ideological and political theory course, higher vocational English, teaching reform, teaching model, micro class and flipped class". The most widely courses using MOOC are two required courses of College English and Ideological and Political Education.The current research is devoted to exploring the teaching model of flipped classroom and micro-lectures based on MOOC platform. Some scholars believe that MOOCs deconstruct the teaching and learning behavior chain in the system of face-to-face communication of traditional classroom ${ }^{[5]}$, and implement the linkage of the four elements:platform, teachers, learners and learning resources ${ }^{[6]}$. Some researchers believe that MOOC provides a new perspective and path for the cultivation of College Students' moral emotion, personality and moral practice experience ${ }^{[7]}$. They devote themselves to explore the main characteristics and basic laws of MOOC education and teaching,and appeal to establish the professional MOOC platform of Ideological and Political Education. Overall, the research on the integration of MOOC and subject teaching is mainly focused on teaching advantage analysis and case analysis of 
application effect, and strongly advocates the localization of MOOC platform. This hotspot is a typical practice of MOOC in Chinese universities, and a major breakthrough in the further development. Future research will attract more subjects to participate and enrich MOOC practice.

Research on the role orientation and service innovation of Libraries under the impact of MOOC. The keywords characterizing this hot topic are library, information literacy, role orientation and service innovation. The research of this topic mainly focuses on the following two aspects. (1)MOOC drives libraries to change roles. It is advocated that libraries should be introduced into teaching teams to become partners in education, not just supporters for teachers.(2)Libraries should actively respond to the impact of MOOC and innovate services.First, libraries should expand educational functions, develop MOOC resources to provide information literacy education, copyright education and cognitive education of Librarian.Second, The existing library management system should be transformed and implemented seamlessly and embedded with the MOOC platform, provide curricular reference materials and extra-curricular extended reading, and carry out thematic push and customization around the course ${ }^{[8]}$. Third, libraries strive to cooperate with the resource providers to solve the copyright problems, and promote the open access and sharing of resources.

Research on Blended Teaching based on SPOC. MOOC is not a panacea. MOOC has obvious defects and difficult to overcome, such as the teaching mode is still the traditional mode,learning experience is not complete, lack of affective communication between teachers and students, learning effect is difficult to evaluate, learning trustworthiness can not guarantee, autonomous learning ability is very demanding, and so on. In order to overcome and remedy the defects of MOOC, SPOC came into being. The essence of SPOC is a school instructional solution that uses MOOC resources for small, specific populations ${ }^{[9]}$. SPOC is the inheritance, perfection and Transcendence of MOOC. It can combine the advantages of MOOC resources and classroom face-to-face teaching, and realize the reconstruction and innovation of the teaching process ${ }^{[10]}$.The academia explores the advantages and disadvantages of MOOC, SPOC and other models and platforms, more importantly, studies the supporting role, function value and model innovation of SPOC for the blended teaching reform. SPOC does have a high fitness degree with traditional teaching, and can solve the defects of MOOC to a certain extent. More flexible and refined courses like SPOC are almost inevitable evolution ${ }^{[11]}$. SPOC should be an important field and development direction that future research and practice must pay attention to.

\subsection{Development suggestions in future}

Actively studing MOOC development strategies and propulsion mechanism. The research on the MOOC development strategies and propulsion mechanism is still in the appeal stage. This appeal includes two aspects: sharing resources between colleges and universities, and the win-win cooperation between schools and enterprises.But few scholars have studied the concrete implementation plan and suggestion of the strategy deployment and the propulsion mechanism construction.However, The correct strategy choice is the basic premise of popularizing MOOC practice, the successful promotion mechanism construction is the basic guarantee for promoting 
the healthy development of MOOC. We must attach importance to research strategies and mechanisms.

Building research community exchange platform to promote cooperation research. The state should set up more MOOC research projects, build international exchanges and cooperation platform, and advocate cross-border, cross regional, cross field cooperation research. The research projects should lay stress on system, integration, practice and innovation, and provide intellectual support and theoretical support for the development of MOOC.

Innovativing business model to attract more enterprises to participate in MOOC construction. The free strategy is unsustainable, because the high quality courses, faculty, and curriculum operations must cost a lot of money. The capital injection without the income sources is difficult to sustain, and the innovation research of the business model is the strict requirement for the development of MOOC. We should keep up with the latest research abroad, actively learn from foreign MOOC profit model, and explore the local business model, attract more educational enterprises to participate in, and inject new vitality into the development of MOOC.

\section{References}

[1]Ym Wang, Am Ye, Wh Lai. Where to Go: Domestic Hotspots Research of MOOC Based on the Knowledge Map Analysis. China Educational Technology,7(2015)12-18. [2]Ym Chai,Zz Li.Visualization and Comparative Analysis of the MOOC Research Hotspots and Frontier Between China and Abroad. Journal of Modern Information, 11(2015)106-113.

[3]Sh TIAN, Xm ZHAO.Analysis and cogitate on knowledge maps of the flipped classroom research in China.Chinese Journal of educational information,6(2016)1-4.

[4]Ya ling MENG, Jizong WEI. The Essence of MOOCs: A New Definition. E-education Research,7(2016)43-49.

[5]Jing ping ZOU. The spirit of MOOC is more important than form. China Distance Education.8(2013)73.

[6]Bing bing CHEN. MOOCs:Contributions and Dilemmas. Computer-assisted Foreign Language Education,3(2014)38-43.

[7]Si Lin AI. MOOC and teaching innovation of Ideological and political theory course in Colleges and Universities. Peking University press,Beijing,2014.

[8]Tianzhen Fu, Jiangping zheng. Strategies of university libraries responding to the MOOC challenge. Journal of University Library,1(2014)22-24.

[9]Yonglin ZHANG,Fengxiang XIAO. SPOC: The deep integration of MOOC and campus curriculum. Chinese Vocational and Technical Education,18(2015)14-19.

[10]Bin He, Yang Cao. SPOC: MOOC-based Innovation of Teaching Processes. China Educational Technology,3(2015)22-29.

[11]Coughlan, S. Harvard plans to boldly go with 'Spocs'[OL].Information on http://www.bbc.co.uk/news/business-24166247. 